\title{
Three Dimensional Transient Explicit Finite Difference Heat Transfer Modeling of Billet Transport
}

\author{
Satish Kumar Dubey*, P. Srinivasan \\ Mechanical Engineering Department, Birla Institute of Technology \& Science, Pilani, Rajasthan, India, 333031
}

\begin{abstract}
In steel industries the billets are heated in reheat furnace. The billets coming out from reheat furnace are transported to the rolling mill. Prediction of billet temperature during transport is vital for several reasons, like energy optimization studies, process simulation, roll force calculation and quality of the final product. Inadequate temperature measuring instruments demands suitable model for billet temperature predictions. In the present work, conduction heat transfer within the billet is modeled using the explicit finite difference method. To solve three dimensional transient discretization equations, code has been developed and implemented in MATLAB ${ }^{\circledR}$. Validation of the proposed numerical model has been done using analytical solutions. The model predictions of billet temperature are shown to be in good concurrence with analytical results. The model is capable of predicting temperature distribution within the billet. The model is used to examine the effect of billet transport velocity on the temperature field of the billet. The objective of this work to apply simple simulation technique to high temperature industrial process for temperature field measurements. This type of simulation may be useful for temperature predictions, design and study of new or existing transport system for hot billet transport.
\end{abstract}

Keywords: Transient, Finite Difference, Explicit, Billet, Heat transfer, Transport

\section{Introduction}

In steel industry the billets are heated up to target temperature in the furnace and then transported to the rolling mills. The target temperature is normally higher than the temperature required in a rolling mill, which is to compensate the heat loss from the billet during transit. The reheated billet is transported to the rolling mills through conveyers. Temperature measurement of the moving component is very difficult due to limited availability of measuring instruments. An experimental investigation are expensive and often impossible. In addition there are various limitation and serious difficulty with measurements attracted researchers toward numerical modeling. There are large number of numerical models are available in literature which are developed for heat transfer predictions [1,2]. A transient heat transfer model for prediction of the temperature of billet in transit is very essential for energy saving, reduction of pollution from the furnace, determination of roll force, roll torque, prediction of microstructure and ensuring the product quality of steel rolling mills. Various reheating process parameters affecting the billet temperature field are studied by different researchers in the recent past. A three dimensional radiative heat transfer analysis using FLUENT ${ }^{\circledR}$ was performed by Kim et al.[3] which gives the temperature distribution in the walking beam furnace. Kim and Kang presented heat transfer analysis by FLUENT $^{\circledR}$ for prediction of the transient temperature distribution in the walking beam reheating furnace [4]. Harish and Duta performed finite volume (FVM) based radiation heat transfer analysis for pusher type reheat furnace. This model predicts radiative flux and resulting temperature distribution in the billet [5]. Jacklic et al. predicted the influence of space between the billets on productivity of walking beam furnace by using Monte Carlo method[6]. Han et al., presented transient radiative heating characteristics analysis. The movement of the slab within walking beam furnace is taken into consideration in their analysis [7]. Jang et al., takes up scale formation and their growth during the formulation of a heat transfer model for reheating furnace [8]. Dubey et al. presented three dimensional heat conduction model for steel billet heating in the reheat furnace [9].

* Corresponding author. Tel.: 91-1596-245073

Fax: +91-1596-244183; E-mail: sdubeybits@ gmail.com

(C) 2013 International Association for Sharing Knowledge and Sustainability

DOI: $10.5383 /$ ijtee. 06.02 .008 
Jacklic et al., presented a three dimensional finite difference model to discuss the effect of thin oxide scale on the temperature of the billet surface during its transport from furnace to rolling mill [10].

In the present work a three dimensional finite difference numerical model for the billet movement process is presented. The simulated model was used for temperature field predictions. Parametric study was done to examine the effect of billet transport velocity on the temperature field of the billet.

\section{Heat transfer and boundary conditions}

During billet transport from reheat furnace to rolling mills its temperature changing with time. Transient temperature profiles for the billet can be obtained using three dimensional transient heat conduction equation for the Cartesian coordinate system which is given by Eq. 1 .

$$
\frac{\partial}{\partial x}\left(k \frac{\partial T}{\partial x}\right)+\frac{\partial}{\partial y}\left(k \frac{\partial T}{\partial y}\right)+\frac{\partial}{\partial z}\left(k \frac{\partial T}{\partial z}\right)=\rho c \frac{\partial T}{\partial \tau}
$$

Heat exchange from billet to surrounding takes place through radiation and convection. All sides of billets are subjected to convective and radiative heat flux. The radiation heat flux is accounted in the present model is factored. The radiation heat flux is given by Eq. 2 [11]

$$
q_{r}=\varepsilon \sigma\left[T_{\infty}^{2}+T^{2}\right]\left[T_{\infty}+T\right]\left[T_{\infty}-T\right]
$$

Radiation heat flux may be combined with convective heat flux and an overall heat transfer co-efficient is given by Eq. 3 .

$\left.h_{\text {total }}=h_{c}+\varepsilon \sigma \mid T_{\infty}^{2}+T^{2}\right][T \infty+T]$

Where convective heat transfer coefficient is evaluated using Eqs (4) and (5) [9]

$h_{c}=0.332 \frac{k_{a}}{x} \operatorname{Pr}^{1 / 3} \operatorname{Re}^{1 / 2}$

$\operatorname{Re}=\rho v_{b} x / \mu$

Air properties used in Eq. 4 and 5 are evaluated at mean film temperature. The initial temperature of billet coming out from reheat furnace is assumed to have uniform temperature of 1523 $\mathrm{K}$. To solve the energy equation, following boundary conditions for billet during transport are used.

For the top horizontal surface and vertical side surface

$-\left.k \frac{\partial T}{\partial x}\right|_{\text {surface }}=h_{\text {total }}\left(T_{\infty}-T\right)$

For bottom surface

$-\left.k \frac{\partial T}{\partial x}\right|_{\text {surface }}=q_{b t}$

Bottom surface nodes that are in contact with conveyors, heat flux $q_{b t}$ for them is calculated from Eq. 8. $q_{b t}=\frac{T \infty-T}{R}$

Where thermal resistance $\mathrm{R}$ is calculated from Eq. 8 .

$R=\frac{1}{h_{c t}}+\frac{d x_{c b}}{k_{c b}}+\frac{1}{h_{c}}$

Contact resistance $\left(h_{c t}\right)$, thickness $\left(d x_{c b}\right)$ and thermal conductivity $\left(k_{c b}\right)$ were taken to be constant [12].

\section{Numerical model}

Finite difference method and explicit formulations are used to approximate differential increment in temperature, space and time. Nodal equations are developed by making transient energy balance on node (i, j, k) by setting the sum of energy conducted, convected and radiated, which is equal to change in internal energy of the node. Explicit method formulates the governing differential equation with respect to previous time step and therefore it does not require any iteration to convergence. The only setback with explicit formulation is stability. In the present study time step is selected to ensure stability criteria for convergence of the numerical solution as suggested by Ozisik [13]. The total time of transport is not very large, makes explicit formulation suitable for billet transport simulation.

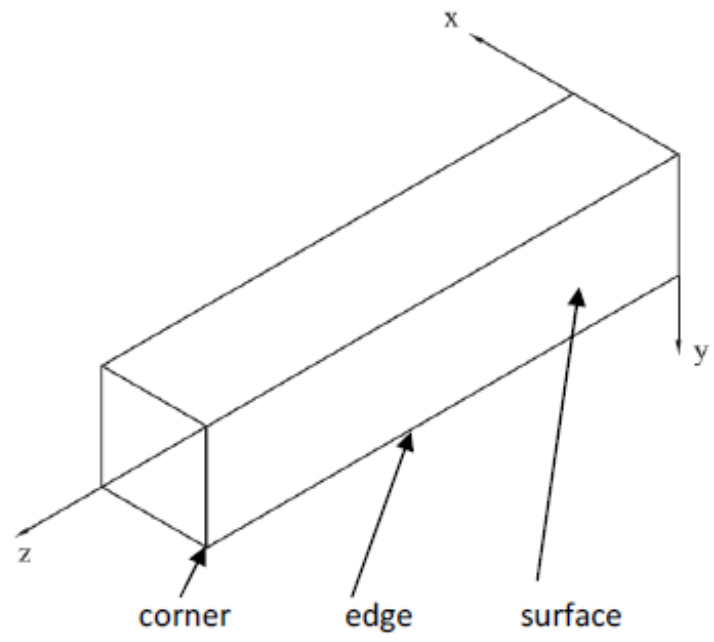

Fig. 1. Billet nodes nomenclature

Finite difference analysis divides billet into finite cells and nodes by descretizing them spatially. Nodes in different positions have different boundary and surrounding nodes, thus different equations are derived for each. The overall heat transfer coefficient (h) used in the above equations is evaluated at previous time step temperature during solutions. The expressions for a corner, edge, surface and inner nodes are given by Eq. 10 to 13 respectively. 
Corner:

$$
\begin{aligned}
T_{i, j, k}^{n+1}= & \frac{2 \alpha \Delta \tau}{\Delta x^{2}}\left[T_{i-1, j, k}^{n}-T_{i, j, k}^{n}\right]+\frac{2 \alpha \Delta \tau}{\Delta y^{2}}\left[T_{i, j-1, k}^{n}-T_{i, j, k}^{n}\right] \\
& +\frac{2 \alpha \Delta \tau}{\Delta z^{2}}\left[T_{i, j, k+1}^{n}-T_{i, j, k}^{n}\right] \\
& +\frac{2 h \Delta \tau}{\rho c}\left[\frac{1}{\Delta x}+\frac{1}{\Delta y}+\frac{1}{\Delta z}\right]\left[T_{\infty}-T_{i, j, k}^{n}\right]+T_{i, j, k}^{n}
\end{aligned}
$$

Edge:

$$
\begin{aligned}
T_{i, j, k}^{n+1}= & \frac{\alpha \Delta \tau}{\Delta x^{2}}\left[2 T_{i-1, j, k}^{n}-2 T_{i, j, k}^{n}\right]+\frac{\alpha \Delta \tau}{\Delta y^{2}}\left[T_{i, j-1, k}^{n}+T_{i, j+1, k}^{n}-T_{i, j, k}^{n}\right] \\
& +\frac{\alpha \Delta \tau}{\Delta z^{2}}\left[2 T_{i, j, k+1}^{n}-2 T_{i, j, k}^{n}\right] \\
& +\frac{2 h \Delta \tau}{\rho c}\left[\frac{1}{\Delta x}+\frac{1}{\Delta z}\right]\left[T_{\infty}-T_{i, j, k}^{n}\right]+T_{i, j, k}^{n}
\end{aligned}
$$

Surface:

$$
\begin{aligned}
T_{i, j, k}^{n+1}= & \frac{\alpha \Delta \tau}{\Delta x^{2}}\left[T_{i+1, j, k}^{n}+T_{i-1, j, k}^{n}-2 T_{i, j, k}^{n}\right]+\frac{\alpha \Delta \tau}{\Delta y^{2}}\left[2 T_{i, j-1, k}^{n}-2 T_{i, j, k}^{n}\right] \\
& +\frac{\alpha \Delta \tau}{\Delta z^{2}}\left[T_{i, j, k+1}^{n}+T_{i, j, k-1}^{n}-2 T_{i, j, k}^{n}\right] \\
& +\frac{2 h \Delta \tau}{\rho c}\left[\frac{1}{\Delta y}\right]\left[T_{\infty}-T_{i, j, k}^{n}\right]+T_{i, j, k}^{n}
\end{aligned}
$$

Internal:

$$
\begin{aligned}
T_{i, j, k}^{n+1}= & \frac{\alpha \Delta \tau}{\Delta x^{2}}\left[T_{i+1, j, k}^{n}+T_{i-1, j, k}^{n}-2 T_{i, j, k}^{n}\right] \\
& +\frac{\alpha \Delta \tau}{\Delta y^{2}}\left[T_{i, j-1, k}^{n}+T_{i, j+1, k}^{n}-T_{i, j, k}^{n}\right] \\
& +\frac{\alpha \Delta \tau}{\Delta z^{2}}\left[T_{i, j, k+1}^{n}+T_{i, j, k-1}^{n}-2 T_{i, j, k}^{n}\right]+T_{i, j, k}^{n}
\end{aligned}
$$

\section{Simulation}

To solve the set of algebraic equations for individual nodes, code has been developed to implement in MATLAB ${ }^{\circledR}$. The thermo-physical properties of billet are assumed to be constant in the present study. The various inputs given in the present simulations are shown in Table 1.

Table 1. Input data for computer simulation

\begin{tabular}{lll}
\hline & Property & Value \\
\hline \multirow{4}{*}{ Billet } & Dimensions: & $140 \times 140 \times 1500\left(\mathrm{~mm}^{3}\right)$ \\
& Initial temperature & $1523(\mathrm{~K})$ \\
& Density & $7000\left(\mathrm{~kg} / \mathrm{m}^{3}\right)$ \\
& Emissivity & 0.7 \\
& Specific heat & $717.52(\mathrm{~J} / \mathrm{kg} \mathrm{K})$ \\
& Thermal conductivity & $31(\mathrm{~W} / \mathrm{m} \mathrm{K})$ \\
& Thickness & $130(\mathrm{~mm})$ \\
Conveyor & Ihermal conductivity & $5(\mathrm{~W} / \mathrm{m} \mathrm{K})$ \\
& Heat transfer co-efficient for contact & $200\left(\mathrm{~W} / \mathrm{m}^{2} \mathrm{~K}\right)$ \\
\hline
\end{tabular}

A grid independent test has been performed to find the optimum number of grid points in billet. The test is carried out by testing with various grid sizes. During testing with various grid sizes a juncture comes when the effect of grid change is very insignificant. Maximum sizes of grid at which results are not changing significantly are chosen, so that computational time and errors are minimized. In the present grid independent study corner node temperature is monitored, as corner node subjected to steeper temperature gradient, hence a greater challenge to solution method. The suitable grid size selected for the present study is $8.75 \mathrm{~mm}$ in width and thickness directions, while that in length direction is $10 \mathrm{~mm}$. The top corner node temperature at two grid sizes of grid sensitive study, which are giving close results are presented in Figure 2 and 3 .

\subsection{Validation}

Validation of proposed three dimensional finite difference model is done with respect to analytical solution. Analytical solutions are available for calculations of transient temperature field, however these are typically confined to simple geometry and boundary conditions.

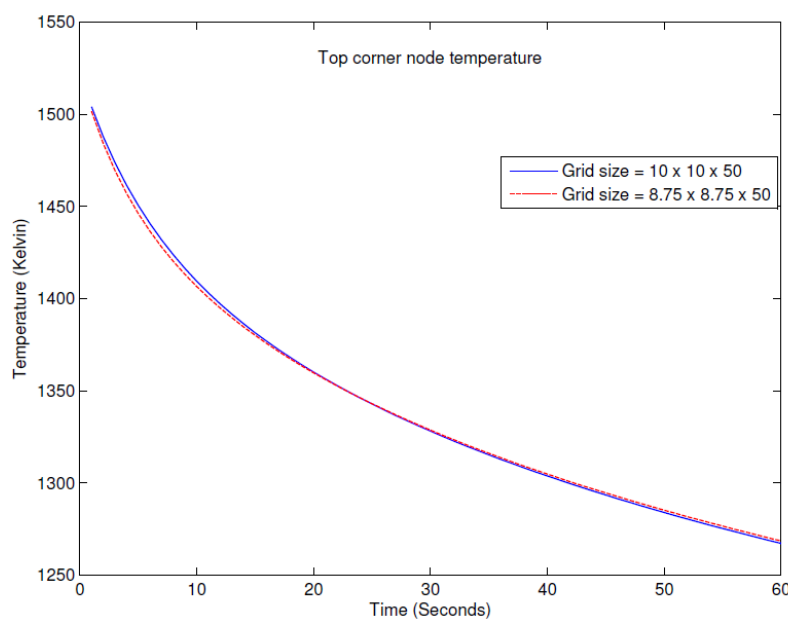

Fig. 2. Grid independence test results for grid sizes in $\mathrm{x}$ and y direction

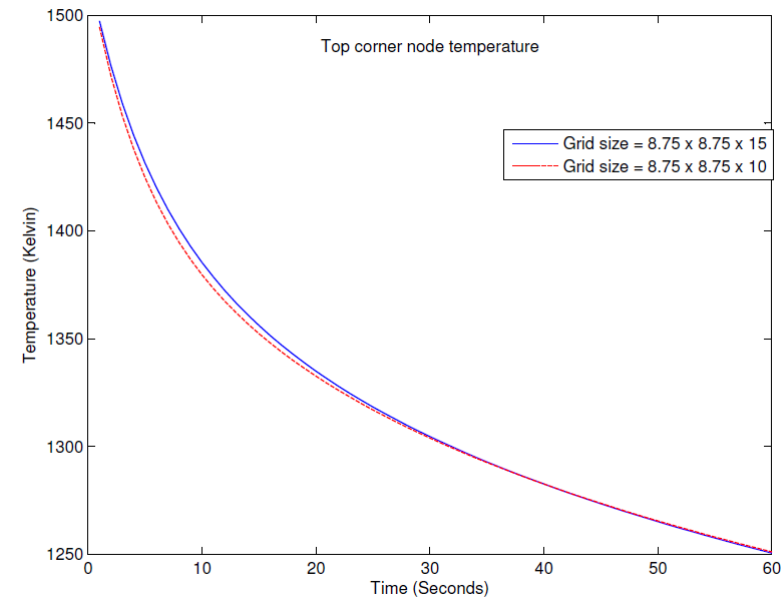

Fig. 3. Grid independence test results for grid sizes in z direction. 
The variable separation method considered here is available for one dimensional, provided all the surfaces exposed to constant temperature fluid with constant heat transfer coefficient. These solutions contain infinite series which has an exponential decay term, so at higher values of dimension less time, terms of summations decline and can be neglected. In the present study of validation, temperatures are calculated for Fo $>0.2$ and only the first term of the series is considered. Three dimensional solution can be obtained by using superposition approach which is also known as product method [11]. The analytical results at any position of billet which is specified by coordinates (x, y, z) and time are calculated using Eqs.(14) to (16).

$$
\begin{aligned}
& \frac{\theta_{1}(x, \tau)}{\theta_{i}}=A_{1} e^{-\lambda_{1}{ }^{2} \tau} \cos \left(\frac{\lambda_{1} x}{L_{1}}\right) \\
& \frac{\theta_{2}(y, \tau)}{\theta_{i}}=A_{2} e^{-\lambda_{2}{ }^{2} \tau} \cos \left(\frac{\lambda_{2} y}{L_{2}}\right) \\
& \frac{\theta_{3}(z, \tau)}{\theta_{i}}=A_{3} e^{-\lambda_{3}{ }^{2} \tau} \cos \left(\frac{\lambda_{3} z}{L_{3}}\right) \\
& \frac{\theta(x, y, z, \tau)}{\theta_{i}}=\frac{\theta_{1}(x, \tau)}{\theta_{i}} \frac{\theta_{2}(y, \tau)}{\theta_{i}} \frac{\theta_{3}(z, \tau)}{\theta_{i}}
\end{aligned}
$$

Where $A$ and $\lambda$ are co-efficient used in one term solution.

The analytical solution obtained through the above method of constant heat transfer co-efficient equal to $153.827 \mathrm{~W} / \mathrm{m}^{2}$. The numerical model conditions are also changed to constant heat transfer coefficient to all sides for comparison. Billet top corner node temperature calculated through analytical and numerical methods are compared. The analytical and numerical results are in good agreement as shown in Figure 4. Increased accuracy was sought at higher time, which is obvious because at a larger value of time, the Fo number will be high as an effect of this other term of the series solution diminishes which yields better analytical solutions.

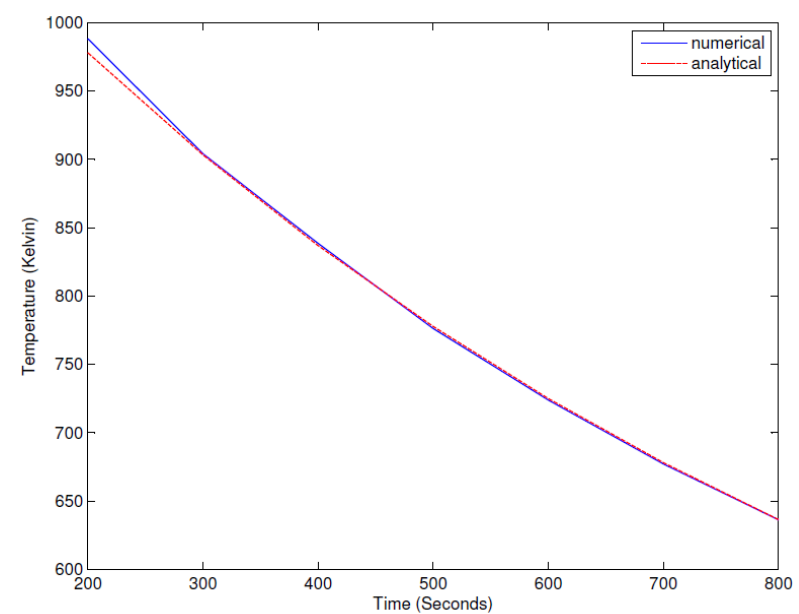

Fig. 4. Validation of numerical model with analytical solution.

\section{Results and discussions}

Results for transient temperature predictions are presented in this section. Parametric studies are also carried out to observe the effect of different billet speed on temperature field, which may be vital in regard of energy efficiency, final product quality, and design of billet transport systems.

\subsection{Temperature Prediction}

Prediction of temperature through simulation corresponding to billet velocity $v b=2 \mathrm{~m} / \mathrm{s}$ are shown in Figure 5 . As expected maximum temperature drop obtained at the top corner node and top surface of the billet. The temperature filed is affected by bottom conditions. The minimum temperature drops obtained at the center and bottom of the billet. The overall temperature drop behavior obtained through the simulations seems to be in agreement with the trend expected.

Temperature predicted at three different planes which are located at $17.5 \mathrm{~mm}, 35 \mathrm{~mm}$, and $52.5 \mathrm{~mm}$ respectively below the top surface are shown in Figure 6. Billet temperature gradient observed during transport of billet become more pronounced with time. The billet temperature gradient may seriously affect the final product quality.

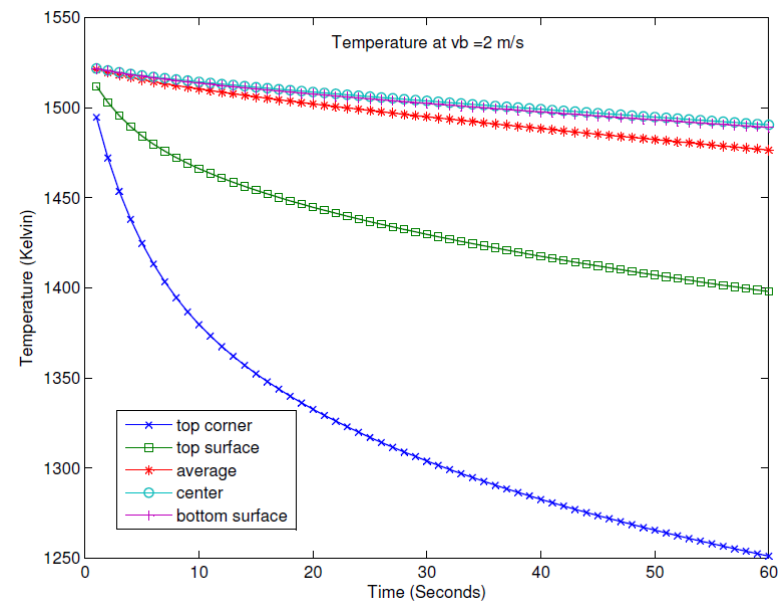

Fig. 5. Simulation result showing the temperature at corner node, surface, bottom, center and average at $\mathrm{vb}=2 \mathrm{~m} / \mathrm{s}$.

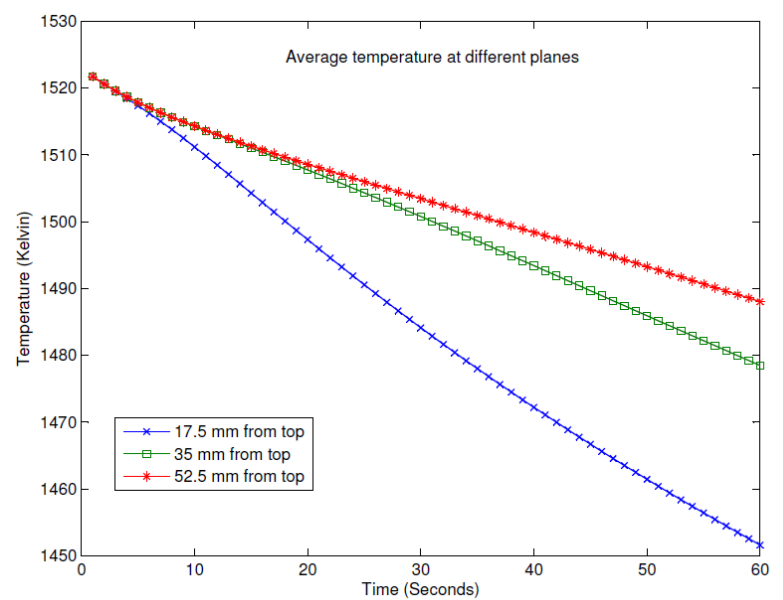

Fig. 6. Simulation result showing billet temperature at three different planes. 


\subsection{Parametric Studies}

The temperature of billet investigated for various values of billet velocity are presented in Figure 7 and 8 . It is observed that the effect of billet velocity over the temperature profiles are not very significant which is expected one, as major heat exchange through high temperature billet is by radiation and role of convection is very limited.

The energy loss from billets during transit is calculated for a case of 100 tonnes per day production, with motive to draw out an idea about the energy lost during transit.

Figure 9 shows energy lost during transit in above case. It is observed from a parametric study that a significant amount of energy is being lost during transport. The lost of energy is mainly by radiation, as the effect of billet transport velocity is negligible. Radiation heat loss during transport can be minimized by reducing travel time with the increase of billet velocity or by modifying transport system with re radiating duct.

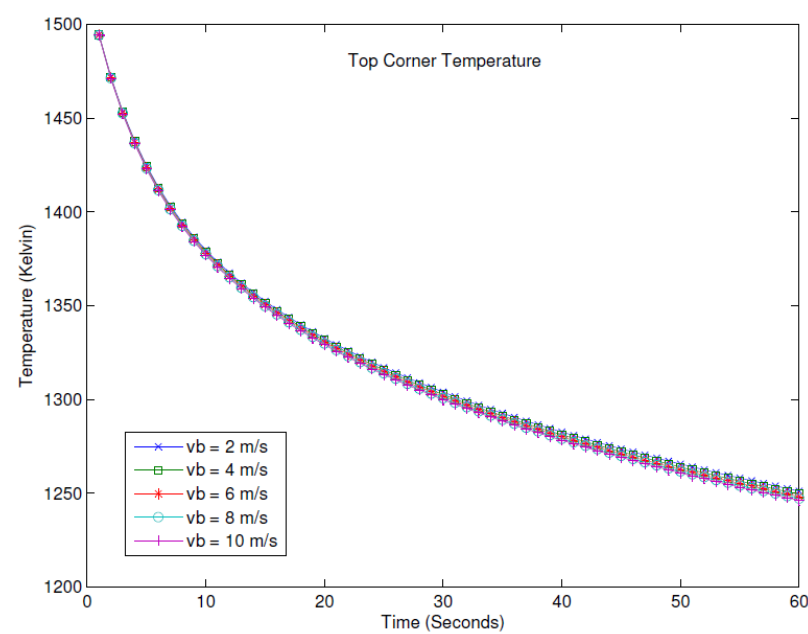

Fig. 7. Simulation result showing billet top corner node temperature at various billet speeds.

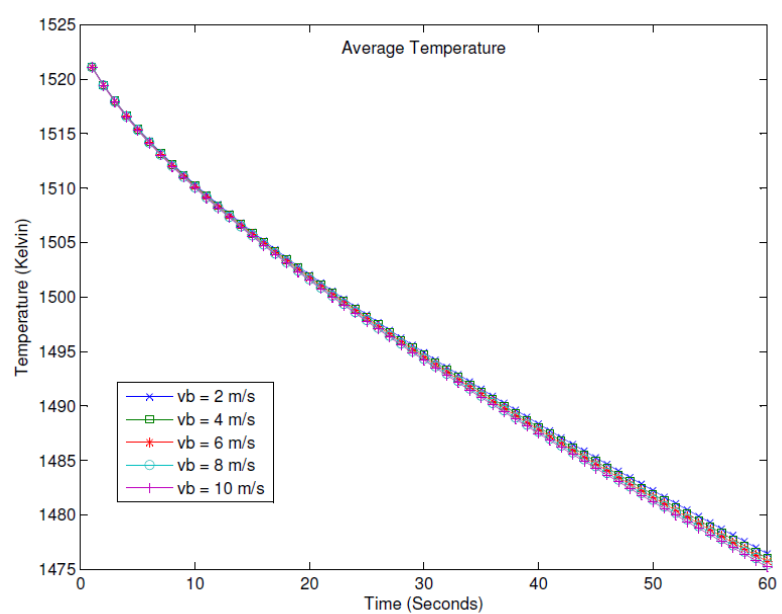

Fig. 8. Simulation result showing billet average temperature at various billet speeds.

\section{Conclusions}

A numerical simulation has been performed using simplified three dimensional explicit finite difference model, for prediction of temperature and for parametric studies. The model is capable to predict the temperature at any node of the billet. Temperature prediction results show that the top surface which is exposed to radiation and convection cools faster and the temperature difference between the top surface and inside surface at some depth increases with time. Parametric studies indicate that higher billet speeds will reduce the energy loss during transport. It is due to less time available for radiation exchange with a very insignificant increase in convection heat exchange.

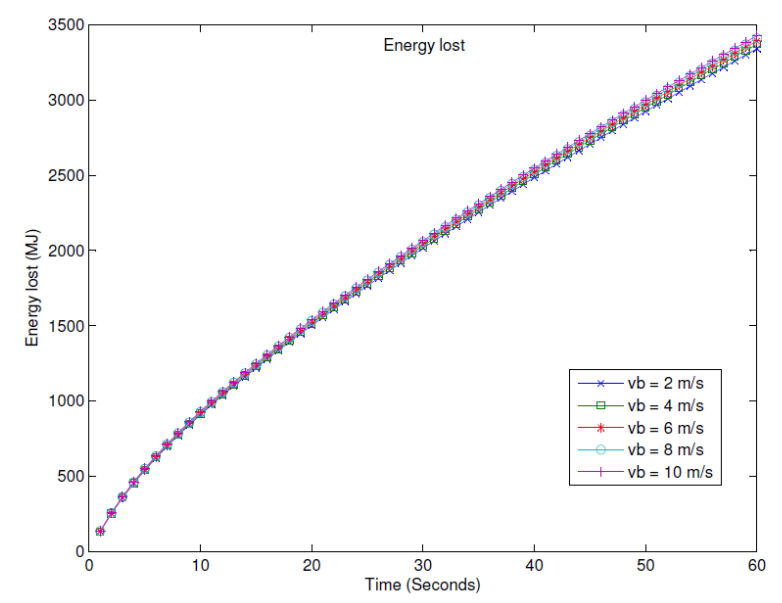

Fig. 9. Simulation result showing energy lost/day during transport for 100 tonnes/day capacity of the plant at different velocity.

\section{Nomenclature}

$\mathrm{dx} \quad$ conveyors thickness over all heat transfer coefficient $(\mathrm{W} / \mathrm{m} 2 \mathrm{~K})$

$\mathrm{T}$ temperature $(\mathrm{K})$

$\mathrm{k}$ thermal conductivity (W/m K)

q heat flux (W/m2)

$\mathrm{R}$ thermal resistance

$\mathrm{v} \quad$ velocity

$\mathrm{x}, \mathrm{y}, \mathrm{z} \quad$ axis of co ordinate system

Greek letters

$\alpha \quad$ thermal diffusivity $\left(\mathrm{m} / \mathrm{s}^{2}\right)$

$\varepsilon \quad$ emissivity

$\sigma \quad$ Stefan Boltzmann constant

$\tau \quad$ time (s)

$\mu \quad$ dynamic co efficient of viscosity $\left(\mathrm{Ns} / \mathrm{m}^{2}\right)$

$\rho \quad$ density $(\mathrm{kg} / \mathrm{m} 3)$

$\theta \quad T-T_{\infty}$ 


$\begin{array}{ll}\text { Subscript } & \\ \mathrm{b} & \text { billet } \\ \mathrm{bt} & \text { bottom } \\ \mathrm{c} & \text { convection } \\ \mathrm{ct} & \text { contact surface } \\ \mathrm{i}, \mathrm{j}, \mathrm{k} & \text { index in } \mathrm{x} \mathrm{y} \mathrm{z} \text { directions } \\ \infty & \text { surrounding } \\ \mathrm{r} & \text { radiation } \\ \text { Superscript } & \\ \mathrm{n} & \text { at } \tau \\ \mathrm{n}+1 & \text { at } \tau+\Delta \tau \\ \text { Non dimensional Numbers } \\ \text { Bi } & \text { Biot number } \\ \text { Fo } & \text { Fourier number } \\ \text { Pr } & \text { Prandtl number } \\ \text { Re } & \text { Reynolds number }\end{array}$

\section{References}

[1] M. Alhajeri.Computational Investigation of Flow and Heat Transfer in Rectangular Duct with Ribs Mounted in a Staggered Arrangement. Int. J. of Thermal \& Environmental Engineering 2012; 1:81:88. DOI: $10.5383 /$ ijtee.04.01.012

[2] M. A. Delavar, F. Mohammadvali. Numerical Simulation of Force Convection in a Channel with Porous Part. Int. J. of Thermal \& Environmental Engineering2013;1:7-14.DOI: 0.5383/ijtee.06.01.002

[3] J. G. Kim, Y. H. Kang, I. T. Kim. Three Dimensional Analysis of the Walking Beam Type Slab Reheating Furnace in Hot Strip Mills. Num. Heat Trans. Part A 2000; 38: 589-609. DOI: $10.1080 / 104077800750021152$

[4] J.G. Kim, Y. H. Kang. Prediction of Transient Temperature distribution in the Re Heating Furnace of Walking Beam Type for Rolling of Steel Slabs.
ISIJ Int. 2000; 40 (11): 1115-1123. DOI: 10.2355/isijinternational.40.1115

[5] J. Harish, P. Dutta. Heat Transfer Analysis of Pusher Type Reheat Furnace. Iron making and Steelmaking 2005; 32(2) : 151-158. DOI: $10.1179 / 174328105 X 23923$

[6] A. Jacklic, T. Kolenko B. Zupancic. The Influence of the Space Between the Billets on the Productivity of Continuous Walking Beam Furnace. App Thermal Eng 2005; 25: 783-795. DOI:10.1016/j.applthermaleng.2004.07.012

[7] S. H. Han, S. W. Beak, M.Y. Kim. Transient Radiative Heating Characteristics of Slab in a Walking Beam Type Reheat furnace. Int. J. of Heat and Mass Trans 2009; 52:1005-1011. DOI:10.1016/j.ijheatmasstransfer.2008.07.030

[8] J. H. Jang, D. E. Lee, M. Y. Kim, H. J. Kim. Investigation of the Slab Heating Characteristics in Reheating Furnace and Growth of Scale on the Slab Surface. Int J of Heat and Mass Trans.2010;53: 43264322.DOI: 10.1016/j.ijheatmasstransfer.2010.05.061

[9] S. K. Dubey, N. Agarwal, P. Srinivasan. Three Dimensional Transient Heat Transfer Model For Steel Billet Heating in Reheat Furnace. Proceedings of the ASME Summer Heat Transfer Conference, Rio Grande, Puerto Rico, USA. 2012; 2 : 963-967. DOI:10.1115/HT2012-58151

[10] A. Jacklic, B. Glogovac, T. Kolenko. A Simulation of Heat Transfer During Billet Transport. App Thermal Eng 2002; 22: 873-883. DOI: 10.1016/S1359-4311(02)00022-4

[11] Y. A. Cengel, A. H. Ghajar. Heat and Mass Transfer. 4th ed. India: Tata McGraw Hill Education Pvt. Ltd.,2011, pp.235-239.

[12] R. L. Howells, S. D. Probert, J. Ward, Influence of Skid Design on Skid Mark Formation. J of the Iron and Steel Inst 1972; 10-15.

[13] M. N. Ozisik. Finite Difference Methods in Heat Transfer. CRC Press, 1994, pp.104-115. 